\title{
Sexual selection and genital allometry in the Hottentot golden mole (Amblysomus hottentotus)
}

Tarryn A. Retief ${ }^{1}$, Nigel. C. Bennett ${ }^{2,3}$, Anouska A. Kinahan ${ }^{1,4} \&$ Philip W. Bateman ${ }^{1,5^{*}}$

${ }^{I}$ Department of Zoology and Entomology, University of Pretoria, Pretoria, 0002, South Africa

${ }^{2}$ Mammal Research Institute, Department of Zoology and Entomology, University of Pretoria, Pretoria, 0002, South Africa

${ }^{3}$ Department of Zoology, King Saud University, Riyadh, Saudi Arabia

${ }^{4}$ Frankfurt Zoological Society-Bale Mountains National Park, PO BOX 165, Robe Bale, Ethiopia

${ }^{5}$ School of Veterinary and Biomedical Sciences, Murdoch University, Murdoch WA 6150, Australia

*corresponding author: pwbateman@zoology.up.ac.za

\begin{abstract}
Under sexual selection, genitalia typically undergo rapid and divergent evolution across species and competition between the sexes over control of fertilisation may drive the co-evolution of male and female sexual traits. Sexual selection can, therefore, influence genitalia in three fundamental but non-mutually exclusive ways: 1) cryptic female choice, 2) sperm competition and 3) sexual conflict. Golden moles (Chrysochloridae) are a highly specialised family endemic to sub-Saharan Africa. We examined intra-specific genital allometry of both male and female subterranean Hottentot golden moles (Amblysomus hottentotus). Consistent with previous studies in mammals, we found positive allometry and a high coefficient of variation (CV) for male genitalia. The results for female reproductive tract length of $A$. hottentotus contrast with the findings of previous studies as isometry was recorded. Based on the allometric
\end{abstract}


relationships of both males and females presented here, we suggest that the males do not sequester females and that in the absence of visual cues the female may use penis size as an indicator of phenotypic quality.

Keywords: Golden mole; Allometry; Genital; Amblysomus

\section{Introduction}

Genitalia typically undergo rapid and divergent evolution across species when under sexual selection (Eberhard, 1985; Arnqvist, 1997; Arnqvist, 1998; House \& Simmons, 2003; Hosken \& Stockley, 2004). In addition, competition between the sexes over the control of reproductive decisions may drive the co-evolution of male and female sexual traits (Arnqvist, 1997). Sexual selection can influence genitalia in three nonmutually exclusive ways: 1) cryptic female choice, 2) sperm competition, and 3) sexual conflict. Under cryptic female choice the prediction is that variation in male genital traits will be related to male fertilisation success; therefore, non-random fertilisation success would be expected among males (Arnqvist, 1997). Sperm competition occurs when the ejaculates of multiple males compete for the fertilisation of an ovum (Hosken \& Stockley, 2004; Parker, Ball, Stockley \& Gage, 1997; Møller \& Birkhead, 1989). Arnqvist (1997) suggested that irrespective of whether males compete directly (via genital morphology) or indirectly (via their ability to stimulate/coerce female sperm use), an element of sperm competition will always be present. The sexual conflict scenario proposes that conflict between the sexes over the control of fertilisation decisions influences the evolution of genitalia (Hosken \& Stockley, 2004; Caizergues \& 
Lambrechts, 1999) which may result in an evolutionary arms race between the sexes in the struggle for the control over reproduction, resulting in the co-evolution of elaborate genitalia (Rice \& Holland, 1997; Hosken \& Stockley, 2004; Caizergues \& Lambrechts, 1999).

Allometric studies (how organs change in size in relation to changes in body size) on genitalia are a useful way of examining the role of sexual selection in the evolution and diversification of these organs and potentially identifying the roles of the three proposed selective features above. Sexually selected traits usually show positive allometry and high phenotypic variation, intimating that the traits increase in size more than would be expected for concomitant body size changes (negative allometry is a less than expected increase in size and isometry is a proportional increase in size) and that directional selection favours wide variation in gene diversity contributing to the trait. Studies on genital allometry have, however, shown a variety of patterns, with arthropod genitalia generally exhibiting a negative allometric relationship between genital size and body size of males (Arnqvist, 1998; Eberhard et al. 1998) as predicted by the 'one size fits all' hypothesis (where males, regardless of body size, have genitalia that fit averagesized females, Eberhard 1985). This pattern reflects the sclerotized, inflexible nature of the arthropod genitalia (e.g. Le Roux et al. 2008). For the small, but increasing, number of studies on mammals the opposite pattern has generally been observed (e.g. Tasikas et al. 2009; Manjerovic et al. 2008; Kinahan et al. 2008; Kinahan et al. 2007; Lüpold et al. 2004; Miller \& Burton, 2001). Kinahan et al. (2007), one of the first studies to include females in the studies of mammal genital allometry, found positive allometry and high coefficients of variation for both male genitalia and female reproductive tract length 
in the African Cape dune mole-rat (Bathyergus suillus) implying an active role of sexual selection in the evolution of that species' genitalia.

Miller \& Burton (2001), Lüpold et al. (2004) and Kinahan et al. (2007) suggested that penis size (as a good genes, phenotypic quality indicator) and positive allometry would play a role for mammals that cannot rely on visual cues to male quality, such as seals in murky water, bats in roosts and mole-rats in lightless burrows respectively (cryptic female choice). The positively allometric testes of $B$. suillus also imply a role for sperm competition (Kinahan et al. 2007). Kinahan et al. (2008) extended this hypothesis to other mole-rat species, and predicted that positive allometry of penises at least may not necessarily be a general pattern for mammals but would be found in those species with the least likelihood of demonstrating any pre-copulatory mate choice. Qualified support for the hypothesis was found in that the social mole-rats species with more complex courtship did not demonstrate positive allometry of the penis as predicted; interestingly neither did another solitary species (Georychus capensis) that was assumed to have a similar mating system to B. suillus, but in G. capensis male seismic drumming during the breeding season may have a role in female assessment of potential mates (Bennett \& Jarvis, 1988).

Golden moles (Chrysochloridae) are a highly specialised family endemic to subSaharan Africa (Bronner \& Bennett, 2005). A group clustered into the Afrotheria, a clade of mammals that probably originated in Africa (see Tabuce et al. 2008), golden moles are totally fossorial and effectively blind. They are cryptic to humans, indicating their presence with slightly raised ridges of soil above their shallow burrows. Very little is known about its behaviour except that females are polyoestrous and aseasonal breeders 
(Skinner \& Chimimba, 2005; Schoeman et al. 2004). We hypothesised that if mating strategies are a major predictor of genital allometry (as suggested for bathyergid molerats; Kinahan et al., 2007, 2008), and if this applies generally to subterranean animals with limited visual acuity then predictions could be made about the mating strategies of the phylogenetically very different golden moles that fill a similar subterranean niche. Similar genital allometric relationships to bathyergids would imply similar mating strategies. In this study we therefore examined intra-specific genital allometry of male and female subterranean Hottentot golden moles (Amblysomus hottentotus).

\section{Methods and Materials}

Amblysomus hottentotus is endemic to South Africa and is one of the more widespread chrysochlorids being regarded as a pest on golf courses and lawns in KwaZulu-Natal. As part of a pest control programme, A. hottentotus were captured from San Lameer $\left(30^{\circ} 56^{\prime} \mathrm{S}, 30^{\circ} 18^{\prime} \mathrm{E}\right)$ and Margate $\left(30^{\circ} 50^{\prime} \mathrm{S}, 30^{\circ} 21^{\prime} \mathrm{E}\right)$ in KwaZulu-Natal Province, South Africa. The golden moles were captured by digging out with a hoe and were killed on site with an overdose of halothane anaesthetic and were subsequently stored in $70 \%$ ethanol. We fortuitously acquired a total of 159 specimens ( 90 females, 69 males) collected by the green keepers as part of an eradication programme by the golf course. Body measurements recorded were body length (nose to the base of the tail), length of skull (tip of bony part of the nose to the back of the skull), width of skull (widest part of the zygomatic arch), front right foot (tip of the longest toe to the tip of the heel of the foot $[\mathrm{SU}]$ ) and hind right foot (tip of the longest toe to the tip of the heel of the foot $[\mathrm{SU}])$. Body length was used as an indicator of body size, since body mass varies 
with individual body condition and across the seasons (see Kinahan et al. 2007, 2008). As adulthood is difficult to identify by tooth wear in afrotherians because of unpredictable tooth eruption patterns (Asher and Olbricht, 2009), we relied on body size as an indicator of adulthood.

Measurements were taken of the reproductive tract length, penis length, testes mass and epididymes mass (dry mass of both left and right). The abdomen of each female was dissected open and the reproductive tract length measured by recording the length from the vaginal opening to where the uterine horns separate. Two penises were dissected out and examined under a scanning electron microscope for evidence of penile spines (see Parag et al. 2006 for methods).

All lengths and widths were recorded using digital calipers to the nearest $\pm 0.01 \mathrm{~mm}$; mass was recorded on a digital scale to $\pm 0.001 \mathrm{~g}$. Each measurement was taken twice for repeatability which was examined by conducting a regression analysis of measurement one upon measurement two (Hosken et al. 2005; Kinahan et al.,2007). The averages of the two measurements for each trait were used in the analyses and left and right testes and epididymes mass were averaged. To reduce the effect of sampling variability, all measurements were taken by the same person (T.A.R.).

The statistical methods used for this study follow those used by Kinahan et al. (2007) using Excel. Data was log-transformed to meet the assumptions of normality. An ordinary least square analysis (OLS) was undertaken to examine the relationships between traits where the slopes of the regression lines were tested for a significant deviation from zero $\left(\beta_{0}\right)$. This was followed by a reduced major axis regression (RMA) to test for allometric relationships (Lüpold et al., 2004, Kinahan et al., 2007). For the 
RMA regressions, $t$-tests were used to examine deviations of the slope of the regression line from a slope of one $\left(\beta_{1}\right)$. When $\beta=1$ in RMA regression, an isometric relationship was inferred, however when $\beta>1$, positive allometry was inferred; similarly, when $\beta<1$, negative allometry was inferred. The coefficients of variation were calculated using the standard method (Sokal \& Rohlf, 1995) and were compared across traits using a modified chi square analysis to compare coefficients of variation (Zar, 1984).

\section{Results}

Table 1 summarises the measurements taken for each trait in both males and females. Amblysomus hottentotus exhibits sexual dimorphism, with males having a significantly longer mean body length than females $(t$-value $=5.59, \mathrm{df}=96, P<0.001)$.

Table 1 Summary data on the range of measurements taken for each trait examined in each sex of Amblysomus hottentotus

\begin{tabular}{llllll}
\hline Body traits & Sex & Minimum & Maximum & Mean & SE \\
\hline Body length $(\mathrm{mm})$ & Male & 74.46 & 97.21 & 86.55 & 0.88 \\
& Female & 60.24 & 94.81 & 79.37 & 0.89 \\
Hind foot (mm) & Male & 12.47 & 15.18 & 14.00 & 0.09 \\
& Female & 10.78 & 14.69 & 12.97 & 0.11 \\
Front foot (mm) & Male & 9.79 & 12.30 & 10.98 & 0.09 \\
& Female & 8.91 & 12.43 & 10.53 & 0.10 \\
Skull width (mm) & Male & 15.90 & 20.40 & 18.11 & 0.14 \\
& Female & 14.18 & 19.40 & 16.69 & 0.14 \\
Skull length (mm) & Male & 28.99 & 37.08 & 31.89 & 0.23 \\
& Female & 26.87 & 33.39 & 29.88 & 0.20 \\
Vagina depth (mm) & Female & 2.67 & 4.49 & 3.79 & 0.07 \\
Penis length (mm) & Male & 1.22 & 2.48 & 1.74 & 0.05 \\
Testes mass $(\mathrm{g})$ & Male & 0.0005 & 0.0106 & 0.0030 & 0.0005 \\
Epididymes mass $(\mathrm{g})$ & Male & 0.0001 & 0.0021 & 0.0008 & 0.0001 \\
\hline
\end{tabular}


The penis of the male showed no spines or other structures. Table 2 shows the summary statistics for both OLS and RMA analyses on measured traits. RMA was conducted only where the ordinary least square regression deviated significantly from zero as according to Sokal \& Rohlf (1995) RMA can overcome scale dependence and when there may be measurement error in independent and dependent variables.

Table 2 Summary statistics for ordinary least squares (OLS, testing for a significant deviation from a slope of zero, $\beta_{0}$ ) and reduced major axis regression (RMA, testing for a significant deviation from a slope of one, $\beta_{1}$ ) analyses for male Amblysomus hottentotus. The percentage coefficient of variation (\%CV), the sample size $(N)$ and the correlation coefficients for each trait $(r)$ are also listed. RMA was carried out only if OLS regression showed a significant relationship between traits. The CV of body length is $7.03 \%$. (a) All non-genital traits ( $y$-axis) regressed against body length ( $x$-axis). (b) Penis length, testes mass and epididymes mass ( $y$-axis) regressed against body length ( $x$-axis). (c) Testes mass and epididymes mass $(y$ axis) regressed against penis length ( $x$-axis).

\begin{tabular}{|c|c|c|c|c|c|c|c|c|}
\hline & $N$ & $\bar{R}$ & $\beta_{0} \pm \mathrm{SE}$ & $t$ value & $\beta_{1} \pm \mathrm{SE}$ & $t$ value & Allometry & $\% \mathrm{CV}$ \\
\hline (a) Hind foot & 47 & 0.15 & $0.09 \pm 0.19$ & 1.01 & & & & 4.14 \\
\hline Front foot & 47 & 0.32 & $0.25 \pm 0.25$ & 2.25 & & & & 5.44 \\
\hline Skull length & 48 & -0.08 & $-0.06 \pm 0.23$ & -0.54 & & & & 4.94 \\
\hline Skull width & 48 & 0.14 & $0.10 \pm 0.24$ & 0.98 & & & & 5.17 \\
\hline (b) Penis length & 31 & 0.44 & $1.18 \pm 1.00$ & 2.67 & $2.66 \pm 1.00$ & 3.75 & Positive & 16.79 \\
\hline Testes mass & 28 & 0.11 & $1.44 \pm 5.83$ & 0.56 & & & & 80.41 \\
\hline Epididymes mass & 25 & 0.32 & $3.06 \pm 4.31$ & 1.61 & & & & 54.55 \\
\hline (c) Testes mass & 28 & 0.53 & $2.65 \pm 1.90$ & 3.17 & $5.03 \pm 1.90$ & 4.81 & Positive & \\
\hline Epididymes mass & 25 & 0.50 & $2.26 \pm 1.86$ & 2.75 & $4.55 \pm 1.86$ & 4.31 & Positive & \\
\hline
\end{tabular}

Males showed no relationship between body length and any of the non-genital measurements. Positive allometry occurred for penis length but no relationship was found for testes mass or epididymis mass. The CV was markedly higher for penis length 
(exhibiting positive allometry), testes mass and epididymes mass than for the non-genital traits.

Females showed no relationship between body length and three of the four nongenital traits (hind foot, skull length and skull width) while front foot length and body length showed a negative allometric relationship (Table 3). Reproductive tract length was isometric with body length but a higher $\mathrm{CV}$ was found for reproductive tract length than for the body measurements.

Table 3 Summary statistics for ordinary least squares (OLS, testing for a significant deviation form a slope of zero, $\beta_{0}$ ) and reduced major axis regression (RMA, testing for a significant deviation from a slope of one, $\beta_{1}$ ) analyses for female Amblysomus hottentotus. The CV of body length is $8.04 \%$. (a) All non-genital traits ( $y$-axis) regressed against body length ( $x$-axis). (b) Reproductive tract length ( $y$-axis) regressed against body length ( $x$-axis). All traits are against body length

\begin{tabular}{lllllllll}
\hline & $N$ & $R$ & $\beta_{0} \pm \mathrm{SE}$ & $t$ value & $\beta_{1} \pm$ SE & $t$ value & Allometry & $\% \mathrm{CV}$ \\
\hline (a) Hind foot & 51 & 0.26 & $0.18 \pm 0.22$ & 1.88 & & & 5.88 \\
$\quad$ Front foot & 51 & 0.44 & $0.33 \pm 0.22$ & 3.38 & $0.76 \pm 0.22$ & -2.42 & Negative & 6.47 \\
$\quad$ Skull length & 52 & 0.14 & $0.08 \pm 0.18$ & 1.01 & & & 4.77 \\
$\quad$ Skull width & 52 & 0.06 & $0.04 \pm 0.23$ & 0.43 & & & 5.97 & \\
$\begin{array}{l}\text { (b) Reproductive tract } \\
\quad \text { length }\end{array}$ & 36 & 0.60 & $0.76 \pm 0.39$ & 4.43 & \multirow{2}{*}{$1.25 \pm 0.39$} & 1.47 & Isometric & 10.94 \\
\hline
\end{tabular}

\section{Discussion}

Sexually selected traits typically exhibit positive allometry with high phenotypic variation since they have been subject to long-term directional selection (Pomiankowski \& Møller, 1995). In this study we found positive allometry and a high CV in the genitalia of male Amblysomus hottentotus, which is typical of sexually selected traits and has been supported by previous studies on mammals (Miller \& Burton, 2001; Lüpold et 
al., 2004; Kinahan et al., 2007; Manjerovic et al., 2008). In the first study of allometry performed on female mammals, Kinahan et al. (2007) found positive allometry and a high CV for female reproductive tract length in Bathyergus suillus. Our findings contrast somewhat with those of Kinahan et al. (2007) as isometry, but a high CV, was found for the female reproductive tract length of $A$. hottentotus. In addition to reproductive tract length, we observed negative allometry for front foot length, although this result was only obtained for females. Although it is difficult to identify with confidence the evolutionary forces acting upon A. hottentotus genitalia, we discuss our results in the light of results obtained by Kinahan et al. (2007) for B. suillus, an animal that occupies a similar ecological niche to the golden mole.

Amblysomus hottentotus is an aseasonally reproductive mammal (Schoeman $e t$ al., 2004). Females are polyoestrous and produce small litter sizes of one or two offspring (Bernard et al. 1994). The absence of penile spines on the penis supports the hypothesis that females are spontaneous ovulators (see Parag et al. 2006). As $A$. hottentotus is effectively blind and subterranean nature, pre-copulatory mate choice by females based on visual assessment of males seems unlikely. There is some evidence to suggest that females communicate their ovulatory status to males acoustically (N.C. Bennett, unpub. data) and that scent marking may play a role in finding mates (they have large olfactory lobes; N.C. Bennett pers. obs.) as has been supported for European mole (Talpa europaea) (Mellanby 1966). Males will attempt to reach females and mate with them and it is possible that several males may converge on a female during her receptive period as territories appear to be small (0.02 ha; Kuyper 1979) and are likely to overlap 
as do those of the Namib desert golden mole (Eremitalpa granti namibensis) (Fielden 1991).

Penis length may confer a benefit for males in terms of likelihood of paternity. In theory, a longer penis would enable a male to deposit an ejaculate closer to the site of fertilisation within the female reproductive tract (Kinahan et al., 2007). This would benefit males undergoing sperm competition with the ejaculates of other males. Testes mass has also been shown to be positively associated with sperm competition in mammals (Harcourt et al. 1981; Gage \& Freckleton, 2003) since larger testes produce proportionally more spermatozoa (Gage, 1995). However, no allometry was found for either testes or epididymes masses of $A$. hottentotus when regressed against body length. These results suggest that for females unable to judge males visually, penis length may be used as a good genes indicator during copulation, as has been suggested for bats (Lüpold et al. 2004). However, genitalia are thought to have co-evolved in both sexes (Eberhard, 1985; Minder et al. 2005; Kinahan et al. 2007), and the same pattern was not found in female golden moles. We suggest that multiple oestrus events per year may allow females to mate with several males and perhaps only allow complete copulations from males with the largest penises, or in some other way manipulate their ejaculates. In other words, their investment lies in iteroparity rather than reproductive tract length.

No relationships were found to exist between any of the non-genital traits and body length in the male; however, negative allometry was found for front foot length in the females. The 'pleiotropy hypothesis' (Mayr 1963) suggests that high inter-specific variation in genitalia is because co-evolution occurs between genetically correlated characters and the effects on genitalia are therefore incidental and selectively neutral. 
Pleiotropy does not explain why this would be seen in genitalia more than in other organs. Adaptive advantages of the observed allometry in length of the highly modified front foot in the females as opposed to males is difficult to ascertain, however, and the possibility of pleiotropy cannot be ruled out although positive allometry has been observed in the femur and tibia lengths of certain vertebrates (Lammers and German 2002, Farlow and Pianka 2000). Consistent with results obtained by Pomiankowski and Møller (1995) coefficients of variation were notably higher in sexual than in non-sexual traits (see also Rowe and Houle, 1996).

The mole-rat Bathyergus suillus is a solitary, subterranean mammal that occupies a similar ecological niche to A. hottentotus although it is a seasonal breeder and an induced ovulator. Although it might be predicted that A. hottentotus would demonstrate similar genital allometry to B. suillus, (Kinahan et al. 2007) our results show some intriguing differences. Both species showed sexual dimorphism, although it is much greater in B. suillus where males may attempt to monopolise several females and compete, both physically and through sperm competition with other males (Thomas et al. 2009, Kinahan et al. 2007). This shows a marked contrast to the behaviour of $A$. hottentotus where there is no evidence that males sequester or control females (N.C. Bennett unpub. data). Sexual selection would, however, be acting strongly on both penis length and sperm production in B. suillus, where the risk of sperm competition may be high during the breeding season. As A. hottentotus is an aseasonal breeder with spontaneous ovulation, sexual selection may have favoured investment in penis length to increase success through female choice. Therefore, although A. hottentotus and B. suillus 
occupy a similar ecological niche, their mating strategy, and consequently the evolutionary forces acting upon their anatomy may be very divergent.

In conclusion, although it is difficult to determine the evolutionary forces and mechanisms responsible for the evolution of genitalia, in this study we find support for the sexual selection hypothesis as the major driving force of genital evolution. This is in agreement with the findings of previous studies of genital allometry in mammals conducted by Manjerovic et al. (2008), Kinahan et al. (2007, 2008), Tasikas et al. (2007) and particularly Lüpold et al. (2004) where the role of the penis as a good genes indicator was mooted. We support the sexual selection hypothesis for several reasons (adapted from Kinahan et al., 2007), even though positive allometry of both male and female genitalia was not found for A. hottentotus. Firstly, there is support accumulating for sexual selection as the driving force responsible for the evolution of genitalia, and the lack of support for e.g. the pleiotropy hypothesis. Secondly, the high phenotypic variation obtained in this study for genital traits is consistent with qualities associated with sexually selected traits. Thirdly, the benefits of investing in sexually selected structures must out-weigh the costs for sexually selected traits (Green, 1992). Any associated costs of the increased investment in penis length would be negated or greatly reduced through the greater reproductive benefits for the males.

\section{Acknowledgements}

We thank San Lameer golf estate in KwaZulu-Natal for the specimens provided to undertake this research. An honours bursary was awarded to T.A.R from the South African Research Chair Initiative of Mammal Behavioural Ecology and Physiology by 
the NRF/DST to N.C.B. The research was supported by a National Research Foundation Grant to N.C.B.

\section{References}

Arnqvist, G. 1997. The evolution of animal genitalia: distinguishing between hypotheses by single species studies. Biol. J. Linn. Soc, 60, 365-379.

Arnqvist, G. 1998. Comparative evidence for the evolution of genitalia by sexual selection. Nature 393, 784-786.

Asher and Olbricht, 2009: Dental ontogeny in Macroscelides proboscideus (Afrotheria) and Erinaceus europaeus (Lipotyphla). J.Mammal.Evol. 16, 99-115.

Bernard, R.T.F., Bronner, G.N., Taylor, P.J., Bojarski, C. and Tsita, J.N. 1994. Aseasonal reproduction in the Hottentot golden mole, Amblysomus hottentotus, from the summer rainfall region of South Africa. S.Afr. J.Sci. 90, 547-549.

Bronner, G.N. and Bennett, N.C. 2005. Afrosoricida. In The Mammals of the Southern African Subregion. Revised by J.D. Skinner and C.T. Chimimba. Cambridge University Press, Cambridge, U.K. pp. 1-21.

Caizergues, A. and Lambrechts, M.M. 1999. Male "macho" mammals exploiting females versus male "Don Juan" birds exploited by females: the opposite-sex exploitation (OSEX) theory. Ecol. Lett. 2, 204-206.

Eberhard, W.G. 1985. Sexual Selection and Animal Genitalia. Cambridge, Massachusetts: Harvard University Press.

Eberhard, W.G., Huber, B.A., Rodriguez, R.L., Briceno, R.D., Salas, I. and Rodriguez, V. 1998. One size fits all? Relationships between the size and degree of variation in 
genitalia and other body parts in twenty species of insects and spiders. Evolution 52, 415-431.

Farlow, J.O. and Pianka, E.R. 2000. Body form and trackway pattern in Australian desert monitors (Squamata:Varanidae): comparing zoological and ichnological diversity. Palaios 15, 235-247.

Fielden, L.J. 1991. Home range and movements of the Namib Desert golden mole, Eremitalpa granti namibensis (Chrysochloridae). J. Zool. Lond. 223, 675-686.

Gage, M.J.G. 1995. Continuous variation in reproductive strategy as an adaptive response to population density in the moth Plodia interpunctella. Proc.R. Soc. Lond. B 261, 25-30.

Gage, M.J.G. and Freckleton, R.P. 2003. Relative testis size and sperm morphometry across mammals: no evidence for an association between sperm competition and sperm length. Proc.R. Soc. Lond. B 270, 625-632.

Green, A.J. 1992. Positive allometry is likely with mate choice, competitive display and other functions. Anim. Behav. 43, 170-172.

Harcourt, A.H., Harvey, P.H., Larson, G.S.G. and Short, R.V. 1981. Testis weight, body weight and breeding system in primates. Nature 293, 55-57.

Hosken, D.J. and Stockley, P. 2004. Sexual selection and genital evolution. Trends Ecol. Evol. 19, 87-93.

Hosken, D.J., Minder, A.M. and Ward, P.I. 2005. Male genital allometry in Scathophagidae (Diptera). Evol. Ecol.19, 501-515. 
House, C.M. and Simmons, L.W. 2003. Genital morphology and fertilization success in the dung beetle Onthophagus taurus: an example of sexually selected male genitalia. Proc. R. Soc. Lond. B 270, 447-455.

Kinahan, A. A., Bennett, N. C., O'Riain, M. J., Hart, L. and Bateman, P. W. 2007. Size matters: genital allometry in an African mole-rat (Family: Bathyergidae). Evol. Ecol. 21, 201-213.

Kinahan, A.A., Bennett, N.C., Belton, L.E. and Bateman, P.W. 2008. Do mating strategies determine genital allometry in African mole rats (Bathyergidae)? J.Zool. Lond. 274, 312-317.

Kuyper, M. A. 1979. A biological study of the golden mole Amblysomus hottentotus. MSc thesis, University of Natal, Pietermaritzburg, RSA.

Lammers, A.R. and German, R.Z. 2002. Ontogenetic allometry in the locomotor skeleton of specialized half-bounding mammals. J.Zool. Lond. 258, 485-495.

Le Roux, E., Scholtz, C.H., Kinahan, A.A. and Bateman, P.W. 2008. Pre- and postcopulatory mate selection mechanisms in an African dung beetle, Circellium bacchus (Coleoptera: Scarabaeidae). J. Insect Behav. 21, 111-122.

Lüpold, S., McElligott, A.G. and Hosken, D.J. 2004. Bat genitalia: allometry, variation and good genes. Biol. J. Linn. Soc 83, 497-507.

Manjerovic, M.B., Kinahan, A.A., Waterman, J.M., Bennett, N.C. and Bateman, P.W. 2008. Structure and allometry of genitalia in males and females of a social African ground squirrel with high polygynandry. J. Zool. Lond. 275, 375-380.

Mayr, E. 1963. Animal Societies and Evolution. Cambridge: Harvard University Press. 
Mellanby, K. (1966). Mole activity in woodlands, fens and other habitats. J.Zool. Lond. $149,35-41$.

Miller, E.H. and Burton, L.E. 2001. Its all relative: allometry and variation in the baculum (os penis) of the harp seal, Pagophilus groenlandicus (Carnivora: Phocidae). Biol. J. Linn. Soc 72, 345-355.

Minder, A.M., Hosken, D.J. and Ward, P.I. 2005. Co-evolution of male and female reproductive characters across the Scathophagidae. J. Evol. Biol. 18, 60-69.

Møller, A.P. \& Birkhead, T.R. 1989. Copulation behaviour in mammals: evidence that sperm competition is widespread. Biol. J. Linn. Soc 38, 119-131.

Parag, A, Bennett, N.C., Faulkes, C.G. \& Bateman, P.W. 2006. Penile morphology of African mole-rats (Bathyergidae): structural modification in relation to mode of ovulation and degree of sociality. J. Zool. Lond. 270, 323-329.

Parker, G.A., Ball, M.A., Stockley, P. \& Gage, M.J.G. 1997. Sperm competition games: a prospective analysis of risk assessment. Proc. R. Soc. Lond. 264, 1793-1802.

Pomiankowski, A. and Møller, A.P. (1995). A resolution of the lek paradox. Proc. R. Soc. Lond. 260, 21-29.

Rice, W.R. and Holland, B. 1997. The enemies within: intergenomic conflict, interlocus contest evolution (ICE), and the intraspecific Red Queen. Behav.Ecol. Sociobiol. 41, $1-10$.

Rowe, L. and Houle, D. 1996. The lek paradox and the capture of genetic variance by condition dependant traits. Proc. R. Soc. Lond 263, 1415-1421 
Schoeman, S., Bennett, N.C., van der Merwe, M. and Schoeman, A.S. 2004. Aseasonal reproduction in the Hottentot golden mole, Amblysomus hottentotus (Afrosoricida: Chrysochloridae) from KwaZulu-Natal, South Africa. Afr. Zool. 39, 41-46.

Skinner, J.D. and Chimimba, C.T. 2005. The Mammals of the Southern African Subregion. Cambridge University Press.

Sokal, R.R. and Rohlf, F.J. 1995. Biometry. Third edition. San Francisco: WH Freeman.

Tabuce, R., Asher R.J. and Lehmann, T. (2008) Afrotherian mammals: a review of current data. Mammalia 72, 2-14.

Tasikas, D.E., Fairn, E.R., Laurence, S. and Schulte-Hostedde, A.I. 2009. Baculum variation and allometry in the muskrat (Ondatra zibethicus): a case for sexual selection. Evol. Ecol. 23, 223-232

Thomas H.G., Bateman P.W., Le Comber S.C., Bennett N.C., Elwood R.W. and Scantlebury M. 2009. Sex differences in burrow architecture and digging activity in the Cape dune mole-rat Bathyergus suillus (Bathyergidae). J. Zool. Lond.279, 277284

Zar, J.H. 1984. Biostatistical Analysis. Prentice-Hall, New Jersey. 